\title{
Computer education and human capacity building for Information Technology in Namibia
}

\author{
Geoffrey E. Kiangi \\ University of Namibia \\ Private Bag 13301, Windhoek, Namibia \\ Tele + 26461206 3620; Fax + 264612063030 \\ E-mail: gkiangi@unam.na
}

\begin{abstract}
Namibia, like many other countries, acknowledges Information Technology's potential in accelerating educational reform. A recently developed computer education policy attempts to ensure that remote schools benefit from the technology by narrowing the gap between the advantaged and disadvantaged schools. Analysis of the policy and the efforts of NITA, the Computer Association of Namibia, to assist in training school teachers are reviewed. The contributions of tertiary institutions, including the University of Namibia, in developing human resources in Information Technology are also examined in order that other developing countries can draw meaningful lessons from Namibia's experience.
\end{abstract}

\section{Keywords}

National policies, computer science, Internet, curriculum development

\section{INTRODUCTION}

Education is a key ingredient in the economy and well-being of any country. Through education, the human resource potential of countries is enhanced and considerable sums of money are spent on human resource development.

Education has continuously undergone reformations. Even in Africa, where formal education is not more than half a century old, many reforms and reviews have been carried out to keep pace with academic and technological developments, and to ensure relevance and equity - although observers have also voiced concern 
about the low level of computer use in the schools of developing countries. They have also warned about the wide gap between developed and developing countries (Kiangi, 1995).

Hawkridge (1991) states four reasons why African schools need computers:

- social - schools are required to prepare students for life. Since computers have pervaded industries, the workplace and the home, students should be expected to be able to handle computers;

- vocational - school children should have a basic knowledge of computers, knowledge that may prepare them for a career in computer science. They also need a foundation that will prepare them to apply computers in the areas in which they will eventually specialize, even if those areas are different from computer science;

- pedagogical - computers are tools through which other subjects can be learned. For example, it is possible to teach a language course by using computerized voices, images and text;

- catalytic - computers can also be used to assist students to learn how to handle information and solve problems without necessarily memorizing facts.

Computers can be a vehicle to encourage collaborative learning while, at the same time, computers catalyze efficiency in the management and administration of schools.

The four reasons given by Hawkridge were the main focal points around which the education policy for Namibia was developed. While they do form good arguments for introducing computer education, there are problems of implementation which will be reviewed later.

The Namibian educational system has undergone considerable changes since independence in 1990. The years since independence can be considered as a phase of education reform and transition, where major organizational, administrative and curricular changes occurred (Ministry of Basic Education and Culture, 1995). Immediately after independence universal education was instituted. A number of studies and discussion were conducted between 1990 and 1992 which shaped future directions. In 1993, Towards Education for All (Ministry of Education and Culture, 1993) translated earlier efforts into concrete implementable government policies. The major goals of the reform effort were outlined as access, equity, quality and democracy. While the goals are not unique to Namibia, the strategic planning that was adopted, and which is now giving dividends, is worth noting.

To manage the reform process, a National Institute for Education Development (NIED) was established within the Ministry of Basic Education and Culture. The major functions of the institute include: curriculum research and development; curriculum implementation, including professional development and in-service teacher training; coordination of pre-service teacher training; and the development and production of instructional materials (Kiangi, 1994).

In February 1995, following the initial phase of reform and transition, NIED conducted a global assessment of the new system to evaluate the effects of 
initiatives adopted in the reform process. Several positive achievements were noted. The number of candidates who sat for grade 12 in 1995 increased six-fold within a period of only 5 years. Many learners are now able to choose their field of study within close proximity to their homes. All senior secondary schools are applying a single unified system in admission, class size and teaching loads so the first two goals of access and equity are beginning to be realized.

There are also problems with the reform process. In some schools teacher inefficiency was noted as a serious problem and it was also noted that it is difficult to have common core subjects in all schools. Computer courses and the popular HIGSCE courses can only be offered by few privileged schools. Availability of textbooks was observed to be a big problem. The few textbooks in use are from Britain and have little relevance to the local situation.

Lack of qualified teachers is also a problem. Namibia has only half the needed teachers for secondary schools in terms of qualifications (University of Namibia, 1995). Proper physical facilities are lacking in many schools. About $21 \%$ of all classrooms in Namibian schools are constructed using sticks, mud and thatch. Promotion rates for some grades range from $43 \%$ to $92 \%$. This means that if the rates remain the same, for every 100 learners starting grade 1 only 3 reach grade 12 (Ministry of Basic Education and Culture, 1995b). This is a very poor throughput and if all these problems are not addressed they can overshadow the benefits of the reform process.

\section{COMPUTERS IN NAMIBIAN SCHOOLS}

\subsection{Courses}

Three courses are offered at different grades: computer literacy (grades 5-7), computer practice (grades 8-10) and computer study (grades 11-12) (Ministry of Basic Education and Culture, 1995; 1996; Kiangi and Hamutenya, 1994).

Computer literacy covers word processing and drawing using programs such as Paintbrush and Logo. Computer practise courses cover programming and advanced elements of computer literacy. Computer study courses cover the social and economic implications of IT as well as system design concepts. Coverage in the courses provides basic knowledge only and does not make one employable as a computer expert.

\subsection{Enrolments}

Only a few schools are able to offer computer subjects. According to 1995 statistics only $67(.05 \%)$ students took Computer literacy; only $2083(2.6 \%)$ students took Computer practice; and only 251 (1\%) students took Computer study (Ministry of Basic Education and Culture, 1995b). Many of the students enroled in computer courses are only from privileged private schools, resulting in very low enrolments given above. 


\subsection{Performance}

Examination results for 1995 are very interesting. The Junior Certificate examination results showed 472 candidates sat for the exam and $12 \%$ were awarded grade A pass - the highest percentage of grade A passes for the 32 subjects that were examined.

IGCSE results showed that 131 students sat for computer studies and $19 \%$ were awarded grade A - one of the three well-passed out of the 43 subjects.

The statistics indicate that computer subjects can be performed well but students lack access to computing resources. Many are denied computer education not because they do not have the ability but because schools lack computer resources or trained teachers. In some schools computers have been donated but collect dust because there are no computer-literate teachers. The 1992 figures indicate that there were only 10 qualified computer teachers for grade 12 (Kiangi and Hamutenya, 1994).

\subsection{Computer Education policy}

For a long time the reform process was carried without much regard to the provision of computer facilities to schools. To a large extent schools were left to decide how to resource themselves. As a consequence, only a few schools acquired computer resources and trained teachers. In early 1995 a debate started on the need to provide a directive for computer education. Kiangi (1995) emphasized that there was a compelling need to develop a computer education policy, stressing the fact that while there are sentiments that computer education is a luxury, especially in a country where schools are still struggling to erect buildings for classes, it is imperative that a policy be set so that the meager resources available for computer education are put to the best use. He cautioned that failing to provide computer subjects - leaving such decisions to individual schools will widen the gap between the privileged schools and the underprivileged. That will greatly undermine government efforts in achieving equity in education.

Since then, the UNESCO office in Namibia provided funds to develop a computer education policy under NIED's direction. A draft policy was prepared by a number of academics, experts and NIED staff. A workshop was convened, calling in a number of teachers to discuss the draft, which was finalized in 1996.

The Computer Education policy is divided into three parts:

- introduction - states the need for a computer education policy and describes how computers impact the society today;

- policy - integrates the computer education policy with existing government objectives and priorities, and identifies the rationales for providing computer education courses;

- implementation - identifies short term, medium term and long term objectives, develops strategies needed to achieve the objectives, and identifies target groups and institutions bearing responsibility for ensuring the success of policy objectives (Ministry of Basic Education and Culture, 1996) 
Very little has been done since the policy was completed. A financial strategy, outlining how the disadvantaged schools can be helped, should have been included. To a large extent, a computer education policy is also a fiscal policy. Since the education policy was based on the four reasons advanced by Hawkridge (1991) - social, vocational, pedagogical and catalytic - it is important to note a few things. Many analysts have examined in detail the pedagogical and catalytic reasons relating to learning. It is interesting that while more literature exist on these two than on the other reasons, it is these reasons that are ignored when African schools decide to introduce computer education. Namibia, therefore, starts on the right footing. With regards to the pedagogical reason, Sewell (1990) argues that computers should be used within the framework of cognition, learning and information processing. He analyses in detail the use of computers as cognitive tools and concludes that computers can be used for cognitive growth. Computers enable expression of skills already existing in a much easier way and they encourage the development of new cognitive skills.

Brown (1985) observes that computers provide an empowering environment where learners can accomplish things they otherwise could not accomplish. Bruner (1966) discusses the social context of computer education in that as students work together on a computer in small groups and group discussions are activated, discussions which could not be achieved in conventional teaching. Such cooperation among learners results in 'group reciprocity' in which learning is enhanced by learners themselves.

Bruner seems to be in agreement with many others who identify as key contributions of computers to education: active involvement with the learning environment; reduction of mental drudgery; better manipulation of information; and enhancement of abstract thought. Analysts generally agree that if educational philosophies, cognitive psychology and computer science are brought more closely together, greater benefits in computer education will be achieved. Teachers, decision makers and researchers should be made aware of the extra benefits not covered in many computer policy statements.

\subsection{Internet}

The introduction of the Internet into Namibian schools has created great interest, although many schools do not know how to effectively use the tool. The dangers of providing Internet access are also great and Internet issues need a separate section in the policy. In fact, since Information Technology is a dynamic field, a mechanism for continuously monitoring IT developments and ensuring harmonious progress should be incorporated in the policy document.

The University of Namibia (UNAM) and the Polytechnic of Namibia are the largest tertiary institutions which offer computing as a specialty. Other tertiary institutions offer computing as a subject; none offer courses beyond computer literacy. Professional computer companies offer short courses on specialized computer application areas. 
The University of Namibia in 1995 enrolled 3501 students, more than half of whom were first year students. Only 169 were science students, 20 of whom majored in computer science. The University does not offer a degree in computer science but offers a Bachelors of Science degree where computer science can be a major together with other science subjects. Students from other faculties can also major in computer science, but with difficulty. Only two to six candidates have graduated annually with B.Sc. degree in computer science, although the numbers are gradually increasing. Beginning 1996, all science students must undertake a computer literacy course.

The Polytechnic of Namibia had an enrollment of 3272 students in 1995 . Nearly half of the students take Information Systems, which is equivalent to computer literacy. The Polytechnic also offers a Business Computing Diploma requiring a one-year National Computing Certificate (NCC) offered by National Computing Centre in UK as well as an additional two years of computer and business studies. Only a few candidates graduate each year with a Diploma in Business Computing and the NCC part of the course was phased out in 1997.

Winschiers (1996) attempted to analyze IT knowledge acquisition of students at the University and Polytechnic. She noted that cultural backgrounds inhibit acquisition of computer knowledge and result in poor conceptions of computer science by students. This observation challenges the way computer education is provided both at tertiary and secondary school levels, and has led the Department of Computing at the University of Namibia to embark upon a research project intended to develop on-line computer training methods taking into account individual students' education backgrounds.

Use of computers in distance education also receives considerable attention. At the end of 1996 the University of Namibia attempted to examine how computers can be used to provide distance education. The University is working with the United Nations Office of Outer Space in Vienna, together with 12 other African countries, in the COPINE project to develop a computerized satellite system which will be used for distance education and many other applications such as telemedicine. The planning for this system is fairly well advanced.

KEY ELEMENTS FOR FUTURE DIRECTIONS

\subsection{The computer education policy}

The computer education policy has been finalized. The policy should be implemented. If a school does not have computers, it can organize visits to a nearby, better-endowed school in order to provide a basic understanding of computers. Once enthusiasm has been created within a school, it is to acquire computers from a number of donor sources, including the local community. There are additional benefits to the implementation of the policy. One study notes that cognitive abilities among African students are low (World Bank, 1988). Since computers are excellent cognitive tools, they can be used to enhance cognitive growth. 


\subsection{Government Internet connection}

The government, through the Directorate of Public Service Information Technology Management in the Prime Minister's office, has embarked upon a comprehensive program of providing all government ministries access to the Internet. The system will provide capabilities to support dedicated and dial-up Internet users, and will allow migration to larger systems as Internet uses expand within the government. The system consists of a series of backbone routers providing a $256 \mathrm{kbps}$ connection to Global One. A total of 25 servers located in various ministries and regional government centres will be provided.

In addition, the Directorate of Public Service Information Technology Management is initiating government-wide online computer training courses. The courses range from simple computer literacy courses to comprehensive specialized courses in different areas of computer applications. This leapfrogging in computer use at the government level is likely to have far-reaching implications. The education system will be under greater pressure to keep pace.

The university computerized satellite system to be launched in association with COPINE will be a powerful tool in providing education in a cost-effective manner. The Ministry of Education may wish to use this for in-service training since computer courses can be offered to school teachers via this system with significant effect.

\subsection{Contribution of NITA}

The Namibian Information Technology Association (NITA) has always had a keen interest in computer education. In the past, the Association has helped train school teachers on Information Technology. Currently, NITA is looking for ways to assist in training school teachers, hoping to boost computer interest in schools.

\subsection{Introduction of Internet}

The introduction of Internet to Namibia has provided an upsurge of interest in IT. Several Internet service providers have mushroomed, Internet cafes have been established and school children flock to them with great excitement. A number of well-endowed schools have obtained Internet connectivity and the upsurge of interest is likely to have profound effect on computer education.

\subsection{Introduction of ISDN technology}

Telecom Namibia is upgrading most telephone lines to a digital system. The ISDN architecture of all digital telephone lines should make it easy to interlink computers requiring 64 to $128 \mathrm{kbps}$ throughputs over long distances. This will accelerate the building of a computer network infrastructure where schools can connect effortlessly, and be able to receive and transmit voice, data and images. Again, such an infrastructure will put pressure on schools to train for and utilize Information Technology. 


\subsection{The IT industry}

While the level of application of Information Technology in the industry and organizations in Namibia is fairly high (Kiangi and Hamutenya, 1994; Winschiers, 1996), IT management in Namibia still has a long way to go. As with any other technology, Namibia is mainly a consumer rather than a developer of Information Technology. There is a critical shortage of IT experts and even the simplest Information Technology applications are developed outside the country. There is little effort either within the government or in industry to localize IT application development. The situation has adversely affected computer education in Namibia. Elsewhere, Ellis (1974) has commented, '...thinking about computers in education does not mean thinking about computers, it means thinking about education'. Government policies should encourage industry to use local manpower in developing IT applications and thereby catalyze IT human resource development.

\section{6}

\section{CONCLUSION}

The experience of Namibia in training learners and experts in Information Technology presents a mixed picture. Excellent efforts such as the development of a computerized satellite system for use in training and the completion of a computer education policy are set against the lack of appreciation on the part of executive authorities of the potential benefits Information Technology can provide to education.

The computerized satellite system that the University of Namibia is developing provides opportunities for a wide range of developments in education such as the in-service training of teachers. Online computer training shows some promise as a viable computer training method with such a system in place.

Namibia has an environment conducive to developing the required Information Technology human resources given the good telecommunication infrastructure, a strong IT user market and close proximity to South Africa, where expertise can be tapped. Given the small population and the large land area, IT applications are particularly attractive to Namibia. Tele-education and tele-medicine seem to be the only way by which goals of education and health for all can be achieved. In recognition of this, IT human resource development should be regarded as essential. Other countries can learn about the good efforts Namibia has attempted in IT human resource development but take note of areas that need strengthening as outlined above.

\section{REFERENCES}

Brown, D. (1985) Process versus product: A perspective on tools for communal and informal electronic learning, in Chen, M. and Paisley, W. (eds.), Children and Microcomputers: Research on the Newest Medium, Sage, Beverly Hills, $\mathrm{CA}$.

Bruner, J. (1966) Towards a Theory of Instruction, Norton, New York. Ellis, A.B. (1974) The Use and Misuse of Computers in Education. McGraw Hill, New York. 
Hawkridge, D. (1991) Computers in Third World schools: African advances. Educational and Training Technology International, 28(1), 55-70.

Kiangi, G. E. (1994) Science, Technology and Mathematics Education in Namibia, CASTME Technical Report. NIED, Ministry of Education and Culture, Windhoek, Namibia.

Kiangi, G.E. (1995) Computer Education and the need for a policy. Journal for Education in Namibia, 1(2), 36-41.

Kiangi, G.E. and Hamutenya, N. (1994) Status of Informatics and Information Technology in Namibia. RINAF South Workshop on Information Technology Networking and Education, Bulawayo, Zimbabwe.

Ministry of Basic Education and Culture. (1996) Policy for Information Technology in Education in Namibia. NIED, Windhoek, Namibia.

Ministry of Basic Education and Culture. (1995) Annual Report. Windhoek, Namibia.

Ministry of Basic Education and Culture. (1995) Education Statistics. Education Management Information Systems (EMIS), Windhoek, Namibia.

Ministry of Education and Culture. (1993) Towards Education for All: A Development Brief for Education, Culture and Training. Gamsberg Macmillan, Windhoek, Namibia.

Sewell, D.F. (1990) New Tools for New Minds. Harvester Wheatsheaf, London. University of Namibia. (1995) Proceedings of the (H)IGCSE colloquium on Teacher Education. Windhoek, Namibia.

Winschiers, H. (1996) Information Technology Diffusion in Namibia. Sim posio de Informatica Informatica e desenvolvimento, Maputo, Mozambique.

World Bank (1988) Education in Sub-Sahara Africa: Policies for Adjustment, Revitalization, and Expansion, A World Bank policy study. World Bank, Washington, D. C..

Geoffrey Kiangi holds a B.Sc. in Civil Engineering from the University of Dar es Salaam, Tanzania (1982), an M.Sc. Construction Engineering from Leeds University, UK, (1984) and a Ph.D. in Engineering Management and Computer Applications, Leeds University (1988). He has worked as a consulting engineer, site engineer and university lecturer at the University of Dar es Salaam, Tanzania and the University of Nairobi, Kenya. He is currently Head of Department of Computing at the University of Namibia. His research interests include software engineering, computer networks, technology management and optimization techniques in engineering. He has written books, several journal and conference papers as well as literature for children in these areas. 